\title{
A Multilevel Study: Factors Influencing Taiwan Primary School Students' ICT Literacy
}

\author{
Yujiao Wang and I-Hua Chen
}

\begin{abstract}
Although information and communication technology (ICT) literacy is a key competence for students in the 21st century, most scholars only focus on ICT literacy in higher education and vocational education, while neglecting to discuss this competence on primary education. Given that it is not clear how various level factors affect primary school students' ICT literacy, this study conducted a multilevel analysis to examine the possible factors influencing primary school students' ICT literacy. The data was released by Taiwan's administrative department in 2013, and the valid sample number is 943 students (including one of their parents) and 89 school deans. The results showed that: 1) The variables at student-level including gender, self-efficacy, ICT application in spare time and family salary income were significantly related to students' ICT literacy; 2) At the school-level, the larger the school size was, the higher the students' ICT literacy was.
\end{abstract}

Index Terms-ICT literacy, multilevel analysis, primary school student, school size.

\section{INTRODUCTION}

The daily environment in the 21 st century is full of information and communication technology (referred to as ICT) products and related applications, which have a significant impact on everyone's life style nowadays. Facing such an information society, the Organization for Economic Cooperation and Development (OECD) pointed that every citizen should have basic ICT literacy in order to be able to adapt well to the life of today's society, and also called upon that all countries should pay more attention to how to effectively develop the ICT literacy of students in compulsory education in order to maintain national competitiveness.

In China, faced with the above-mentioned world educational trends, the administrative departments of education also make the cultivation of students' ICT literacy an important educational policy, such as the general implementation of information technology courses in primary and secondary schools, and the construction of various national computer examinations. These policies are

Manuscript received June 20, 2020; revised October 26, 2020. This work was supported by Science and Technology Innovation Team Project of Liupanshui Normal University (Project No. LPSSYKJTD201603), Key Discipline Construction Project of Education in Liupanshui Normal University (Project No. LPSSYZDPYXK201704), and The Plan of Teachers' Professional Development and Promoting Effectiveness Evaluation of Primary and Secondary Schools in Action Learning in Taiwan's "Ministry of Education" (Project No. B103-E07).

Yujiao Wang is with the School of Educational Science, Liupanshui Normal University, Guizhou, China (e-mail:Wangyj_psych@yeah.net).

I-Hua Chen is with the Chinese Academy of Education Big Data, Qufu Normal University, Shandong, China (e-mail: aholechen@gmail.com). indeed helpful for the development ICT students' literacy. In terms of the ICT education research, however, most scholars focus only on higher education and vocational education [1]-[3], and empirical studies on ICT literacy of primary school students are rare. This problem is not unique in China. Scholars have also found similar phenomena in many countries [4]. What factors will promote the ICT literacy of primary school students? What factors adversely affect literacy? These important issues need to be clarified by empirical research. Since the compulsory primary education stage is the basis for follow-up studies of pupils, it is necessary to explore the relevant factors affecting the ICT literacy of primary school students.

Based on this, the researchers conducted an empirical study about Chinese primary school students' ICT literacy. In order to test the relevant factors affecting the ICT literacy of primary school students more comprehensively, a multilevel analysis (Hierarchical Linear Model) was conducted in this study, which included the variables of student-level and school-level. This method can avoid the inference bias when dealing with the nested data and address the dependent problem of the nonindependent sampling, which makes the results to be more accurate.

\section{SElection of Study VARiables AND Hypothesis DEDUCTION}

The student-level variables selected by this study include: gender, self-efficacy, ICT application in spare time and family salary income (which is called salary income for short); the school-level variables are ICT equipment support and school size. The following part further explains the reasons for variable selection and proposes corresponding research hypotheses.

\section{A. Gender}

The difference between genders has always been the focus of scholars' attention in related ICT research [5], [6]. The reason why it is valued is that the overall ratio of women choosing computer science as a direction of further education and employment is significantly lower than that of men. This serious problem should be paid attention to. The existing empirical evidence suggests that differences of ICT literacy between sexes may only gradually differentiate after secondary school, while the difference between male and female primary school students is not significant, as reflected in the cross-country study of Reinen and Plomp [6]. Recently, however, Hohlfeld, Ritzhaupt and Barron re-examined the impact of gender on ICT literacy by means of multilevel analysis, and drew conclusions that differ from traditional conclusion using $\mathrm{T}$ analyses [5]. Our study also used a 
multilevel analysis model, and controlled relevant variables into the model, hoping to accumulate more empirical data on the impact of gender variables on ICT literacy. The researchers initially assume that ICT literacy of boys and girls were different (research hypothesis $\mathrm{H}_{1}$ ).

\section{B. Self-efficacy}

The past empirical data showed that the motivation to use ICT had a rather critical effect among the relevant factors affecting students' ICT behavior [7], [8], and self-efficacy is the more frequently mentioned variable in the field of learning motivation research [9]. Therefore, this study includes self-efficacy in the test. Meelissen pointed out that in the study of students' ICT literacy, self-efficacy is often defined as the self-ability perception that individuals can use computers to accomplish a certain task without the assistance of others [4]; Kay thought that self-efficacy can be regarded as an attitude of individuals' towards computer use [10]. According to Meelissen and Kay, it seems that the higher the student's self-efficacy in ICT literacy is, the more likely this positive attitude is to make individual be more willing to engage in ICT related activities, and then the higher the ICT literacy is. Therefore,we assume that the higher the students' self-efficacy is, the higher the ICT literacy is (research hypothesis $\mathrm{H}_{2}$ ).

\section{ICT Application in Spare Time}

The ICT application in spare time refers to the general name of students using ICT to engage in various tasks during the spare time. Many studies have found that students more frequently engage in ICT application activities in spare time, compared with school information technology courses only once or twice a week [11], [12]. Kuhlemeier and Hemker's research showed that [13] there is a significant positive correlation between ICT activities students used at home, such as e-mail, web chat and paperwork, and their ICT literacy. Therefore, we assumed that students' ICT application in spare time is positively correlated with their ICT literacy (research hypothesis $\mathrm{H}_{3}$ ).

\section{Salary Income}

Salary income refers to the monthly income that a student's family obtains. Salary income reflects the environmental conditions support that the family environment can provide for students to engage in ICT activities. Past empirical studies have paid little attention to the relationship between family salary income and students' ICT literacy, so researchers lack direct evidence to infer the relationship between them, but there is still an indirect evidence from the Digital Divide research. Research on the digital divide has found that there is a lower proportion of people who engage in ICT behaviour in less developed regions because of the economic, social and infrastructure factors [14]. On this basis, we assumed that the higher the family salary income is, the better the family support network environment is, and the higher the students' ICT literacy is (research hypothesis $\mathrm{H}_{4}$ ).

\section{E. ICT Equipment Support}

In this study, ICT equipment support specifically refers to the environmental support provided by school for students to engage in ICT activities. Students in the same school use the same equipment, and they are jointly affected by the same environmental context, so using the multilevel analysis model, researchers assume that school ICT equipment support has a positive impact on students' ICT literacy (research hypothesis $\mathrm{H}_{5}$ ).

\section{F. School Size}

School size is a common variable in multilevel analysis [15]. Mostly, the larger the school size is, the easier it is to sit in the more developed cities, while smaller schools are mostly in the towns. In one hand, past empirical studies have shown students in remote villages and towns are with lower ICT literacy than students in large-scale schools in urban areas because of the uneven distribution of resources [16]. In another hand, there is usually large class size in large schools[17], and past study found that the reduction of class size helps to improve students' learning effectiveness [18]. Therefore, the existing studies can not accurately infer the impact direction of school size on ICT literacy, and the researchers can only assume that there is a correlation between the two, but can not assume its direction (research hypothesis $\mathrm{H}_{6}$ ).

\section{RESEARCH METHODS}

\section{A. Research Framework}

The research framework proposed by the researchers is shown in Fig. 1. $\mathrm{H}_{1}-\mathrm{H}_{4}$ are the direct impacts of the student-level variables on the ICT literacy, and $\mathrm{H}_{5}$ and $\mathrm{H}_{6}$ are the direct impacts of the school-level variables in students' ICT literacy.

\section{B. Research Objects and Sampling Methods}

In this study, the original data which were released by the survey of "Digital Learning and Digital Opportunities for 6 to 11 Years Old" conducted by the Taiwan Administration in 2013 are used as the source of data analysis. The survey is based on the stratified sampling of classes number and students number of the National primary school data in Taiwan. Survey objects are selected primary school students, students' parents, and school deans.

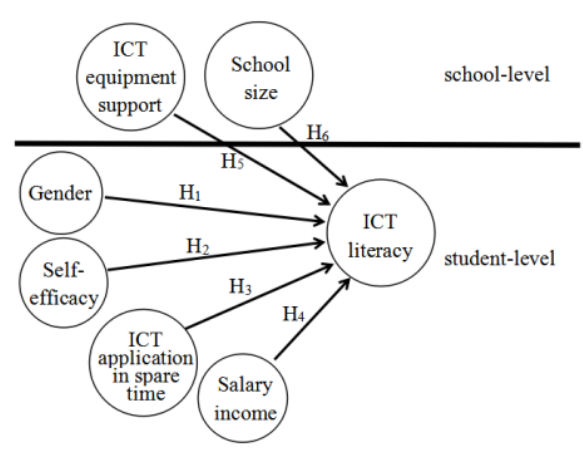

Fig. 1. Research framework.

The testing method is that the commissioner went to the selected schools, and test the students in the classroom. The students were then asked to bring the questionnaire home to their parents to fill out. The questionnaires will be withdrawn by the class instructors within three days, and will be sent 
back by school. The school dean fills in the school part of the questionnaire, and the questionnaires will be withdrawn by the commissioner when handling student questionnaires.

After filtering the data (including the questionnaires of incomplete answers, uncertain response in the answer, and unable to make the connection of students and parents), there were total 943 valid students ( 455 boys and 488 girls) and their parents involved in this study. Besides, 89 school deans were also included as the data source of school-level variables.

\section{Data Measurement}

The data measurement of this study includes student-level and school-level variable groups. The data of gender, self-efficacy, ICT application in spare time of the student-level variables were taken from the student questionnaire; the salary income information was obtained from the corresponding parent questionnaire. The number of school's ICT equipment support and school size of school-level variables were obtained from the school deans' questionnaire.

The variables measured in this study include a single indicator, formative indicators and non-psychological constructs measurement (i.e., no measurement error). Except that the single measurement indicator can not be presented a quantitative reliability and validity values, the reliability and validity of other variables are as follows.

\section{1) ICT equipment support}

The ICT literacy measured by this study includes three modules: students' computer hardware operating ability (for example: power on, power off, install mouse and print files), computer software operating ability (for example: install software, use word processing software) and the ability to search for information on the Internet. Based on the content of the questionnaire, students evaluate whether they can operate the item stated in ICT literacy (options are: can and can not). There are 19 items in total, the choice of "can" will count as 1 , and the choice of "can not" will count as 0 , so ICT literacy scores range from 0 to 19 , and the higher the score is, the higher the ICT literacy is.

Since the 19 measurement items of ICT literacy are not necessarily high correlated (for example: people with high hardware operation ability may not have high software operation ability), so the measurement of ICT literacy is a composite indicator. At present, there is still no comprehensive approach to test the reliability and validity of composite indicator, but most scholars believe that there should be no serious multivariate collinearity problems between composite measurement indicators, which will reduce the reliability and validity of the measurement model [19], [20]. Based on this, the researchers carried out the multiple collinearity detection with the 19 items, and results showed that VIF values which reflects the severity of the collinearity problem are between 1.21 and 2.22, which meet the standard that the value should be less than 3.3. It is obvious that there is no existing multivariate collinearity, which also means that the reliability and validity can be ensured.

2) Self-efficacy
The student's self-efficacy measured by this study refers to the self-confidence of using the computer to complete the homework teachers assigned independently. There is only 1 question. The options include two, one is that "I can complete independently (score 1) " and "I can not complete independently (score 0 )". Although this study uses only one item to measure student's self-efficacy, which is a relatively rare method. But because a single item has direct and convenient advantage in measurement, some scholars still believe that the reliability and validity of a single item are not necessarily lower than the measurement index using multiple items [21], [22]. More importantly, the item that measure student's self-efficacy in this research fit perfectly with Meelissen's opinion of self-efficacy in ICT research [4], thus it has content validity.

\section{3) ICT application in spare time}

The ICT application in spare time is a measurement of degree of students' involvement in ICT applications autonomously, which includes four questions: writing emails, searching data, social networking, typing documents, etc. There are two options: take activities (score 1) and no activities (score 0 ). So the score is from 0 to 4 points, and the higher the score is, the more autonomous the student is involving in ICT application in spare time. Seen form the composition of four measurement items, the measurement model is also consistent measurement indicators (because writing emails frequently does not necessarily searching for data frequently), so researchers still used multiple collinearity detection method to check whether the reliability and validity of the measurement model is subject to the threats of multiple collinearity. The result showed that the VIF values of the four items range from 1.01 to 1.03 , which means there is no collinearity problem, so the reliability and validity of the measurement model are ensured.

\section{4) Salary income}

The measurement of salary income is 1 item, including 16 options, measuring the family's total monthly salary income, and the higher the score is, the higher the family's salary income is. The variable of salary income is not a potential construct, and there is no measurement error, so the reliability and validity may not be discussed.

\section{5) School's ICT equipment support}

School's ICT equipment support measures the degree to which the school's ICT equipment provides support when students engage in ICT activities at school. There are two items, and one question is to ask the school dean about the degree of the computer grade meeting the students' needs, and the options are: fully meet (score 3), partially meet (score 2) and completely not meet (score 1) in order; another question is to ask whether the software that the school has opened for students meet their needs, and options are: meet (score 2) and not meet (score 1). The total score of the school's ICT equipment support ranges from 2 to 5 points, and the higher the score is, the higher the degree of the support provided by the school's ICT equipment to students is. Since there is not necessarily a correlation between two measurement items, so the measurement model formed by these two measurement items and school equipment support 
construct are also constitutive measurement indicators. Researchers still checked their reliability and validity based on the existence of multiple collinearity. The result showed that the VIF values of the two items are 1.03 and 1.10 , which are lower than the recommended reference value of 3.3 , indicating that there is no collinearity problem, and the reliability and validity of the measurement model are good.

\section{6) School size}

School size measures the total number of students enrolled in the school. The larger the total number is, the larger the school size is. This variable is not a potential construct, and it is no measurement error, so there is no need to discuss its reliability and validity.

\section{Data Analysis}

The variables analysis in this study covers the student individual and the school-level, in order to avoid the inference errors that may arise from different levels of analysis units, so multilevel analysis is the most appropriate method. In addition, because the original data used in this study are class-based sampling, the interdependence of students in the class will be contrary to the assumption of independent sampling of the default data of the traditional corollary statistics. Xiao [15] pointed out that when such nested data sampled nonindependently were processed by traditional statistical analysis, it will result in false research results in which null assumptions are easily rejected, so it is necessary to use multilevel analysis.

\section{RESEARCH RESULTS}

\section{A. Descriptive Statistics and Correlation Coefficient Results}

Table I lists descriptive statistics (a) and the correlation coefficients (b) between variables for all measured variables. The correlation coefficients in the table only display the correlation values in the student-level variable groups and the school-level variables groups, not specifying the values associated with a cross-level group of variables. As far as the results of student-level variable groups, Table I shows that the associations between the variables (i.e., independent variables) used to explain the impact on students' ICT literacy (i.e., dependent variables) are significant, and the direction of the coefficients conforms to the hypothesis of this study.

\section{B. Model and Hypothesis Testing}

According to recommendations of Raudenbush and Bryk [23], multilevel analysis includes the execution of four submodels: Null Model, Random Coefficient Model, Intercepts as Outcomes Model, and Slopes as Outcomes Model. However, because this study does not specifically explore the effect of choroid regulation effect of school-level variable groups, Slopes as Outcomes Model is not analyzed. In the first three models, Null Model is used to test the proportion of intergroup variation in the overall variation of students' ICT literacy (i.e., the choroid effect between different schools), which provides a rational basis for subsequent multilevel analysis; Random Coefficient Model is used to test the direct impacts of student-level variables on ICT literacy; and Intercepts as Outcomes Model is used to test the direct impacts of environment level variables on ICT literacy.

\begin{tabular}{ccc}
\multicolumn{3}{c}{ TABLE I (A): DESCRIPTIVE STATISTICS } \\
\hline \hline Variables & \multicolumn{2}{c}{ Descriptive statistics } \\
\hline school-level & Average & Standard deviation \\
ICT equipment support & 4.70 & 0.56 \\
School size & 500.98 & 670.26 \\
student-level & & \\
ICT literacy & 13.36 & 3.57 \\
ICT application of after & 2.76 & 0.77 \\
school time & & 3.63 \\
Salary income & 6.89 & \\
Gender & & \\
Self-efficacy & & \\
\hline \hline
\end{tabular}

(1) Variables such as gender, self-efficacy can not be presented the average and standard deviation because the measurement scale is nominal; (2) The reference group of gender is female; and the reference group of self-efficacy is students who do not have confidence to complete ICT homework independently; (3) Average salary income is 6.89, which corresponds to a monthly household wage income of approximately RMB 10,000 to 12,000 .

\section{1) Null model}

Null Model does not include any explanatory variables in the model, and is set as follows:

$$
\begin{gathered}
\text { Level } 1 \text { : ICT literacy } i j=\beta_{0 j}+\gamma_{i j} \\
\text { Level } 2: \beta_{0 j}=\gamma_{00}+U_{0 j}
\end{gathered}
$$

According to Table II, the intragroup variation component of students' ICT literacy is 11.28 , and the intergroup variation component is 1.52 , which is significantly not equal to $0\left(\chi^{2}=213.88, p=0.00\right)$, that is, there is a significant variation in students' ICT literacy between different schools. According to calculation, the intragroup correlation coefficient (ICC) is 0.12 , which reaches the moderate correlation intensity as defined by Cohen, indicating that the intergroup variation of students' ICT literacy can not be ignored, so multilevel analysis is necessary to reduce the result bias.

\section{2) Random coefficient regression model}

Except the variables of gender and self-efficacy are not Uncentered in this model, the rest variables of student-level (ICT application in spare time and salary income) are Grand Centered. The pattern is as follows:

Level 1: ICT literacy $i j=\beta_{0 j}+\beta_{1 j}\left(\right.$ Gender $\left._{i j}\right)+\beta_{2 j}$ (Self-efficacy $\left.{ }_{i j}\right)+\beta_{3 j}$ (ICT application in spare time $\left.{ }_{i j}\right)+\beta_{4 j}$ (Salary income ij) $+\gamma_{i j}$

Level 2: $\beta_{0 j}=\gamma_{00}+U_{0 j}$

$\beta_{1 j}=\gamma_{10}+U_{1 j}$

$\beta_{2 j}=\gamma_{20}+U_{2 j}$

$\beta_{3 j}=\gamma_{30}+U_{3 j}$

$\beta_{4 j}=\gamma_{40}+U_{4 j}$

In above settings, $\gamma_{10}, \gamma_{20}, \gamma_{30}$, and $\gamma_{40}$ represent the estimated parameters of the association of student-level variables (gender, self-efficacy, ICT application in spare time, and salary income) and ICT literacy, respectively. The results show that the coefficients reach significant level $\left(\gamma_{10}=-0.58\right.$, se $=0.22, \quad T$-ratio $=-2.59, \quad p=0.01 ; \quad \gamma_{20}=2.08, \quad s e=0.21$, $T$-ratio $=9.71, \quad p=0.00 ; \quad \gamma_{30}=1.59, \quad s e=0.15, \quad T$-ratio $=10.25$, 
$p=0.00 ; \gamma_{40}=0.12, s e=0.03, T$-ratio $\left.=4.23, p=0.00\right)$. The results mean that those female students, students with higher self-efficacy in their own ICT ability, students with more autonomous in spare time ICT activities and students with higher family income ICT literacy are higher, so the research hypothesis $\mathrm{H}_{1}, \mathrm{H}_{2}, \mathrm{H}_{3}$, and $\mathrm{H}_{4}$ are supported. Compared to Null Model, the researchers further calculate that increasing interpretation $\mathrm{R}^{2}$ of student-level variable groups on ICT literacy is $26.00 \%$.

In addition to verifying the parameter values of the coefficients, using random coefficient regression model, researchers also judged whether the slope of $\tau_{11}$ (gender), $\tau_{22}$ (self-efficacy), $\tau_{33}$ (ICT application in spare) and $\tau_{44}$ (salary income) varied. Results showed that variation component of $\tau_{33}$ slope reached significant levels $\left(\chi^{2}=81.08, d f=60, p=0.04\right)$. So it is clear that there are differences between schools in the impact of ICT application in spare time on their ICT literacy, which means there should be some variables at the school level have the effect of choroid regulation between the association of ICT applications in spare time and ICT literacy. However, this part is not in the scope of this study, so slopes as outcomes model is not tested, and the relevant test procedures can be left to future research for further analysis.

TABLE I (B): CORRELATION COEFFICIENT

\begin{tabular}{|c|c|c|c|c|c|c|c|}
\hline Variables & $\begin{array}{l}\text { ICT equipment } \\
\text { support }\end{array}$ & $\begin{array}{l}\text { School } \\
\text { size }\end{array}$ & ICT literacy & $\begin{array}{l}\text { ICT application in spare } \\
\text { time }\end{array}$ & $\begin{array}{l}\text { Salary } \\
\text { income }\end{array}$ & Gender & $\begin{array}{l}\text { Self- } \\
\text { efficacy }\end{array}$ \\
\hline \multicolumn{8}{|l|}{ school-level } \\
\hline ICT equipment support & 1.00 & & & & & & \\
\hline School size & -0.08 & 1.00 & & & & & \\
\hline student-level & & & & & & & \\
\hline ICT literacy & & & 1.00 & & & & \\
\hline ICT application in spare time & & & $0.32 *$ & 1.00 & & & \\
\hline Salary income & & & $0.09 *$ & $0.11 *$ & 1.00 & & \\
\hline Gender & & & $0.16^{*}$ & $-0.08^{*}$ & -0.02 & 1.00 & \\
\hline Self-efficacy & & & $-0.07 *$ & 0.03 & 0.04 & -0.03 & 1.00 \\
\hline
\end{tabular}

TABLE II (A): A MULTILEVEL ANALYSIS OF STUDENTS' ICT LITERACY

\begin{tabular}{|c|c|c|c|c|c|c|}
\hline \multirow[b]{2}{*}{ Fixed Effect } & \multicolumn{3}{|c|}{ Null Model } & \multicolumn{3}{|c|}{ Random Coefficient Model } \\
\hline & $\gamma$ Coefficient & S.E. & $p$ & $\gamma$ Coefficient & S.E. & $p$ \\
\hline$\gamma_{00}$ & 13.19 & 0.18 & 0.00 & 11.85 & 0.22 & 0.00 \\
\hline Gender $\gamma_{10}$ & & & & -0.58 & 0.22 & 0.01 \\
\hline Self-efficacy $\gamma_{20}$ & & & & 2.08 & 0.21 & 0.00 \\
\hline ICT application after school time $\gamma_{30}$ & & & & 1.59 & 0.15 & 0.00 \\
\hline \multirow{3}{*}{\multicolumn{7}{|c|}{$\begin{array}{c}\text { Salary income } \gamma_{40} \\
\text { ICT equipment support } \gamma_{01} \\
\text { School size } \gamma_{02}\end{array}$}} \\
\hline & & & & & & \\
\hline & & & & & & \\
\hline & $\begin{array}{c}\text { Variant } \\
\text { component }\end{array}$ & $\chi^{2}$ & $p$ & $\begin{array}{c}\text { Variant } \\
\text { component }\end{array}$ & $\chi^{2}$ & $p$ \\
\hline$\tau_{00}$ & 1.52 & 213.88 & 0.00 & 0.63 & 57.70 & $>0.50$ \\
\hline$\tau_{11}$ & & & & 10.86 & 63.84 & 0.34 \\
\hline$\tau_{22}$ & & & & 0.29 & 51.75 & $>0.50$ \\
\hline$\tau_{33}$ & & & & 0.45 & 81.08 & 0.04 \\
\hline$\tau_{44}$ & & & & 0.004 & 46.19 & $>0.50$ \\
\hline$\sigma^{2}$ & 11.28 & & & 8.36 & & \\
\hline
\end{tabular}

TABLE II (B): A MULTILEVEL ANALYSIS OF STUDENTS' ICT LITERACY

\begin{tabular}{cccc}
\hline & & & \\
& Intercepts as Outcomes Model & \\
\hline Fixed Effect & $\gamma$ Coefficient & S.E. & $p$ \\
$\gamma_{00}$ & 11.84 & 0.22 & 0.00 \\
Gender $\gamma_{10}$ & -0.58 & 0.22 & 0.01 \\
Self-efficacy $\gamma_{20}$ & 2.06 & 0.21 & 0.00 \\
ICT application after school time $\gamma_{30}$ & 1.59 & 0.16 & 0.00 \\
Salary income $\gamma_{40}$ & 0.10 & 0.03 & 0.00 \\
ICT equipment support $\gamma_{01}$ & 0.22 & 0.19 & 0.27 \\
School size $\gamma_{02}$ & 0.001 & 0.001 & $p$ \\
& Variant component & $\chi^{2}$ & $>0.50$ \\
$\tau_{00}$ & 057 & 55.78 & 0.34 \\
$\tau_{11}$ & 1.00 & 64.03 & $>0.50$ \\
$\tau_{22}$ & 0.22 & 52.04 & 0.03 \\
$\tau_{33}$ & 0.48 & 81.36 & $>0.50$ \\
$\tau_{44}^{2}$ & 0.004 & 45.72 & \\
$\sigma^{2}$ & & & \\
\hline \hline
\end{tabular}




\section{3) Intercepts as outcomes model}

Except the variables of gender and self-efficacy are not Uncentered in this model, the rest individual are Grand Centered. The pattern is as follows:

Level 1: ICT literacy $i j=\beta_{0 j}+\beta_{1 j}\left(\right.$ Gender $\left._{i j}\right)+\beta_{2 j}($ Self-efficacy $\left.{ }_{i j}\right)+\beta_{3 j}$ (ICT application in spare time $\left.{ }_{i j}\right)+\beta_{4 j}($ Salary income $\left.{ }_{i j}\right)+\gamma_{i j}$

Level 2: $\beta_{0 j}=\gamma_{00}+\gamma_{01}\left(\right.$ ICT equipment support $\left._{j}\right)+\gamma_{02}($ School size $\left._{j}\right)+U_{0 j}$

$\beta_{1 j}=\gamma_{10}+U_{1 j}$

$\beta_{2 j}=\gamma_{20}+U_{2 j}$

$\beta_{3 j}=\gamma_{30}+U_{3 j}$

$\beta_{4 j}=\gamma_{40}+U_{4 j}$

According the results of Table II, only $\gamma_{02}$ of school size reaches a significant level $\left(\gamma_{02}=0.001, s e=0.001, T\right.$-ratio $=3.72$, $p=0.00$ ) in the variables of school-level, so $\mathrm{H}_{6}$ is supported, showing that only the school size directly impact students' ICT literacy in the variable groups of school-level. Compared with the random coefficient regression model, after the researchers further calculated that the values of the variable components, corresponding variation component value of the students' ICT literacy decreased from 0.63 to 0.57 , that is the introduction of choroid variables can effectively reduce the degree of school environmental level intercept variation up to $10 \%$.

\section{DISCUSSION}

\section{A. Direct Effects of Student-Level Variables on ICT Literacy}

The results of this study show that the student-level variables including gender, self-efficacy, ICT application in spare time and salary income have a significant effect on students' ICT literacy. Further explanations are given in the following.

First of all, the results of this study showed that, even with multilevel analysis and the inclusion of relevant variables (e.g. student family salary income) into model control, girls' ICT literacy in primary schools are still significantly higher than that of boys. This finding is quite surprising and is not consistent with past empirical findings [6], [24]. That is to say, findings from past studies showing no significant differences in ICT literacy between boys and girls may not be correct. To answer these questions, more empirical research materials including more provinces and countries are needed to be tested to clarify the impact of gender on students' ICT literacy.

The second is the impact of self-efficacy on ICT literacy. With regard to the impact part of self-efficacy, Kay [10] and Meelissen et al. [4] argue that students' self-efficacy for applied ICT is closely related to their literacy, and this study provides empirical evidence support for what they discussed. This result also reminds teachers to pay attention to cultivating students' self-confidence in applied ICT, except for demonstrating the steps of ICT product operation in primary school teaching. Liao and Oescher [25] found that cooperative learning can have a positive effect on students' self-efficacy when applied to teaching. Therefore, based on the results of this study, the researchers suggest that teachers should adopt cooperative learning style when conducting ICT teaching, which will help to improve the self-efficacy of students' operating ICT.

Moreover, according to the effect of ICT application in spare time on ICT literacy, this study found that students' ICT application in spare time can provide positive help for students' ICT literacy. The results can be reasonably explained from the point of view of Somekh et al. [12] and Ten Brummelhuis [11], who believe that students prefer to ICT activities in their spare time. According to the results of this study, even if students are engaged in leisure and entertainment activities such as social networking, chatting, writing email, etc., these activities still contribute to the improvement of their ICT literacy. The results also remind parents to allow students to engage in ICT leisure and entertainment activities at home moderately, and should not completely prohibit the use of ICT products.

The fourth finding of this study is that salary income has a positive effect on students ICT literacy. It is reasonable to understand that the higher the salary income of a student's family is, the more conditions and resources the parents naturally have to build good computer hardware and software equipment and provide a faster network speed, thus increasing the willingness of students to engage in ICT activities at home, which may thus have indirect help for students' ICT literacy. However, it requires parents to be willing to support their students to engage in ICT related activities at home, otherwise, if there is no willingness to support, no matter how high the salary income is, it may not be willing to invest in the hardware and software equipment configuration in home. That means that the two variables of salary income and parent support may have the potential interaction effect on students' ICT literacy. Past empirical studies rarely explored the impact of salary income on students' ICT literacy. Indeed, some studies show that family support helps improve students' ICT literacy [26], [27]. Based on the result of this study, it is suggested that future studies may further examine the interaction effect of two variables on ICT literacy, which makes the analysis of this research topic more in-depth.

\section{B. The Direct Effect of School-Level Variables on ICT Literacy}

This study found that only the school size has a significant impact on students' ICT literacy in the school-level variables, and that the larger the school size is, the higher their ICT literacy is. Why school size has a positive impact on students' ICT literacy? It is possibly because that large-scale schools are usually located in large cities, and according to research related to the digital divide [16], students in developed cities differ greatly from students in remote areas in ICT resource acquisition, which also means that there is still an obvious gap in students' ICT literacy between urban and rural areas, and it is natural to cause students in large-scale schools in urban areas to have higher ICT literacy than students in small-scale schools in rural and urban areas. The results of this study show that there is still digital divide in Taiwan, and action to eliminate the digital divide is still necessary.

In terms of ICT equipment support, there may be two possibilities about ICT equipment support in schools not 
having an impact on students' ICT literacy. The first possibility is this school ICT equipment support is measured by the school deans of education, not students. ICT equipment may be sufficient for the faculty, but the results do not necessarily agree with the students' opinions. Secondly, it is also possible that, students prefer to engage in ICT related activities on personal computers at home, and therefore, the ICT equipment support of the school has not a significant impact on their ICT literacy, as found in past empirical studies [11]-[13].

\section{CONCLUSION}

ICT literacy is one of key competence that students need to adapt to the 21 st century society. Although the administrative department of education in China has implemented relevant policies to improve students' ICT literacy, the empirical research on primary school students' is still insufficient, and so far it is not clear what factors have positive and negative effects on primary school students' ICT literacy. Based on this, this study examined the effects of student-level variables and school-level variables on students' ICT literacy with multilevel analysis. The results showed that: 1) gender, self-efficacy, ICT application in spare time and family income of student-level variables are significantly related to students' ICT literacy, in which the ICT literacy of female primary school students are higher than that of male students, the ICT literacy of high-salary family students are higher than that of low-salary families, and the higher the student's self-efficacy is, the more time the ICT application in spare time is, the higher the students' ICT literacy is; 2) The school-level is that the larger the school size is, the higher the students' ICT literacy is, as the large-scale schools are usually located cities, that is, urban students have higher ICT literacy.

\section{CONFLICT OF INTEREST}

The authors declare no conflict of interest.

\section{AUTHOR CONTRIBUTIONS}

I.-H.C. conducted the research, analyzed the data; Y.J.W. wrote, reviewed and edited the paper, I.-H.C. implemented project management and funding acquisition. All authors had approved the final version.

\section{REFERENCES}

[1] Q. Y. Yang, "Reform of the teaching mode of computer skills in secondary vocational schools," Vocational and Technical Education, no. 20 , pp. $34-35$, July, 2008.

[2] S. L. Ji, "Analysis on computer skills teaching in vocational middle school," China Vocational and Technical Education, no. 18, pp. 36-37, June, 2007.

[3] X. L. Li, Z. L. Du, and M. Li, "Analysis on how to develop students' computer application skills in computer teaching," Gansu Science and Technology, vol. 21, no. 5, pp. 189-191, May, 2005.

[4] M. Meelissen, Computer Attitudes and Competencies among Primary and Secondary Students, New York: Springer, 2008.

[5] T. N. Hohlfeld, A. D. Ritzhaupt, and A. E. Barron, "Are gender differences in perceived and demonstrated technology literacy significant? It depends on the model," Educational Technology Research and Development, vol. 61, no. 4, pp. 639-663, August, 2013.
[6] L. J. Reinen and T. Plomp, "Information technology and gender equality: a contradiction in terminus?" Computers \& Education, vol. 28, no. 2, pp. 65-78, February, 1997.

[7] R. G. He, "A review and prospect of Taiwan's educational science and technology," Education in Taiwan, no. 674, pp. 41-47, April, 2012.

[8] Y. R. Lai, C. Y. Liang, and G. C. Huang, "Study on the demand of E-bag in senior secondary school," Educational Materials and Libraries, vol. 41, no. 1, pp. 119-138, September, 2003.

[9] M. Y. Chen and J. Y. You, "Examine the influence of ability belief and task values on mathematics achievement of eighth grade students in Taiwan by TIMSS data," Educational Science Research Journal, vol. 58, no. 3, pp. 153-186, September, 2013.

[10] R. Kay, "Addressing gender differences in computer ability, attitudes and use," Journal of Educational Computing Research, vol. 34, no. 2, pp. 187-211, March, 2006.

[11] A. C. A. Ten Brummelhuis, ICT Monitor, Enschede: University of Twente, 1998.

[12] B. Somekh et al., ImpaCT2: Pupils' and Teachers' Perceptions of ICT in the Home, School and Community, Coventry: Becta, 2002.

[13] H. Kuhlemeier and B. Hemker, "The impact of computer use at home on students' internet skills," Computers \& Education, vol. 49, no. 2, pp. 460-480, September, 2007.

[14] W. L. Bai, Y. Liu, and Y. Liu, "The evaluation of e-government online service from the perspective of digital divide analysis-an empirical study based on Beijing," Intelligence Science, vol. 32, no. 9, pp. 118-124, September, 2014.

[15] J. C. Xiao, A Study of Multilevel Patterns in Creativity: Theoretical Methods and Practices, Tainan: Taicheng Publishing House, 2013.

[16] C. Q. Zhang, "Bridging the digital divide: Theory and practice of information rights protection for vulnerable groups in America," Mao Zedong and Deng Xiaoping Theory Research, no. 4, pp. 98-103, April, 2012.

[17] Y. T. Song, J. M. Qiu, F. L. Zeng, X. Y. Liu, and B. X. Chen, "Discussion on the effect of basic academic test in junior middle schools," Educational Science Research Journal, vol. 54, no. 2, pp. 59-83, June, 2009.

[18] R. G. Ehrenberg, D. J. Brewer, A. Gamoran, and J. D. Willms, "Class size and student achievement," Psychological Science, no. 2, pp. 1-30, May, 2001.

[19] D. Straub, M.-C. Boudreau, and D. Gefen, "Validation guidelines for IS positivist research," Communications of the Association for Information System, vol. 13, pp. 380-427, March, 2004.

[20] S. Petter, D. Straub, and A. Rai, "Specifying formative constructs in information systems research," MIS Quarterly, vol. 31, no. 4, pp. 623, 2007.

[21] L. Bergkvist and J. R. Rossiter, "The predictive validity of multiple-item versus single-item measures of the same constructs," Journal of Marketing Research, vol. 44, no. 2, pp. 175-184, May, 2007.

[22] J. P. Wanous, A. E. Reichers, and M. J. Hudy, "Overall job satisfaction how good are single-item measures?" Journal of Applied Psychology, vol. 82, no. 2, pp. 247-252, April, 1997.

[23] S. W. Raudenbush and A. S. Bryk, Hierarchical Linear Models: Applications and Data Analysis Methods, Thousand Oaks, CA: Sage, 2002.

[24] I. Vekiri and A. Chronaki, "Gender issues in technology use: perceived social support, computer self-efficacy and value beliefs, and computer use beyond school," Computer \& Education, vol. 51, no. 3, pp. 1392-1404, November, 2008.

[25] H. J. Liao and Oescher, "Cooperative learning: is it a panacea for improving the self-efficacy and task values of English grammar learners?" Education and Psychological Research, vol. 32, no. 3, pp. 25-54, September, 2009.

[26] H. C. Hsiao, Y. L. Tu, and H. N. Chung, "Perceived social supports, computer self-efficacy, and computer use among high school students," The Turkish Online Journal of Educational Technology, vol. 11, no. 2, pp. 167-177, April, 2012.

[27] A. Harris and J. Goodall, "Do parents know they matter? Engaging all parents in learning," Educational Research, vol. 50, no. 3, pp. 277-289, September, 2008.

Copyright (C) 2021 by the authors. This is an open access article distributed under the Creative Commons Attribution License which permits unrestricted use, distribution, and reproduction in any medium, provided the original work is properly cited (CC BY 4.0). 
Yujiao Wang was born in Hebei province, China, in 1986. She received the master's degree in basic psychology from School of Psychology, Southwest University in 2013, which is located in Chongqing, China. She is now studying for the doctor's degree in educational administration at Krirk University, Bangkok, Thailand.

Since September, 2013, she has been working in the School of Educational Science, Liupanshui Normal University in Liupanshui city of Guizhou province, China. Her current interests are application of secondary data analysis in educational and psychological problems.
I-Hua Chen was born in Taibei City, Taiwan R.O.C in 1981. He received the doctor's degree in Education Research Institute, National Cheng-Kung University of Taiwan, in 2014, majoring in digital learning and psycho-metrics.

He was with Guizhou University of Finance and Economics, Guizhou Province, China, from June 2014 4.1. III In Iine to June 2015, and with Dhurakji Pundit University,
Bangkok, Thailand, from July 2015 to July 2016 . He is now a professor in the Chinese Academy of Education Big Data, Qufu Normal University in Qufu City of Shandong Province, China. His current interests are application of digital learning and psycho-metrics in educational technology problems. 